\title{
HASIL TANGKAPAN DAN UPAYA PENANGKAPAN IKAN PELAGIS KECIL YANG TERTANGKAP DENGAN PUKAT CINCIN DI SELAT MALAKA TAHUN 2003-2004
}

\author{
Tuti Hariati")
}

\begin{abstract}
ABSTRAK
Riset perkembangan pemanfaatan sumber daya ikan pelagis kecil yang tertangkap dari Selat Malaka pada periode bulan Mei 2003 sampai dengan April 2005 bertujuan untuk memperoleh data dan informasi perkembangan upaya (jumlah trip dan jumlah hari di laut), daerah penangkapan, komposisi hasil tangkapan, dan laju tangkap terutama jenis ikan pelagis kecil. Metode yang digunakan adalah survei dan pengambilan contoh hasil tangkapan dari kapal yang representatif di lokasi riset (Tanjung Balai). Hasil riset menunjukkan, jumlah trip kapal pukat cincin Tanjung Balai selama tahun 2003 dan 2004 turun dibandingkan dengan tahun 1996 dan 1997, karena peningkatan jumlah hari efektif dan lama di perjalanan dalam tiap trip. Daerah penangkapan selain di seputar perairan Gosong Berhala (Sumatera Utara) juga telah berkembang sampai dengan ke perairan Aceh Timur. Hasil tangkapan didominasi oleh ikan layang (Decapterus spp), sedangkan pada periode tahun 1996 sampai dengan 1997 jenis ikan pelagis kecil yang dominan adalah ikan banyar dan kembung (Rastrelliger spp). Laju tangkap (catch per unit of effort) ikan pelagis kecil pada periode tahun 2003 sampai dengan 2004 dan periode tahun 2004 sampai dengan 2005 masing-masing 710,9 $\mathrm{kg}$ per hari dan $521,0 \mathrm{~kg}$ per hari, turun dari laju tangkap ikan pelagis kecil pada periode tahun 1996 sampai dengan 1997 masing-masing 935,9 kg per hari dan 1831,7 kg per hari. Disarankan agar jumlah kapal pukat cincin yang beroperasi di perairan Selat Malaka tidak ditambah.
\end{abstract}

KATA KUNCl: ikan pelagis kecil, pukat cincin, Selat Malaka

ABSTRACT: The catch and fishing effort of small pelagic fishes caught by purse seiner in the Malacca Straits in year 2003 to 2004. By: Tuti Hariati and Ria Faizah

The research on development of exploitation of small pelagic fishes caught in the Malacca Strait in the period of Mei 2003 to Mei 2004 aims to get data and information of the development of effort (number of trip and number duration of days at sea), fishing ground, catch composition, and catch rate especially of the small pelagic fishes. The methods used were survey and sampling of the catches from the representative vessels in the location of research (Tanjung Balai). The results show that the number of trip of the purse seiner of Tanjung Balai during the year of 2003 and 2004 decreases from the year 1996 and 1997, due to the increasing of the efective days and duration of journey in one trip. The fishing grounds were not only in surrounding of Gosong Berhala waters but it is also developed to the waters of eastern Aceh. The catch of Tanjung Balai's purse seiener during this period of research was dominated by scads (Decapterus spp.) while in the period of 1996 and 1997 it was dominated by mackere/s (Rastrelliger spp.). The catches per unit of effort of small pelagic fishes during the period of 2003 to 2004 and 2004 to 2005 were $710.9 \mathrm{~kg}$ per day and $521.0 \mathrm{~kg}$ per day respectively; the decreases of the catch per unit of efforts of both periods of 1996 and 1997, were $1935.9 \mathrm{~kg}$ per day and $1831.7 \mathrm{~kg}$ per day, respectively. It suggests to keep the number of purse seiner operated in the Malacca Straits in "Status Quo".

KEYWORDS: small pelagic, fishes purse seine, Malacca Strait

\section{PENDAHULUAN}

Di Selat Malaka wilayah Indonesia, sumber daya ikan pelagis seperti ikan layang, banyar, kembung, dan tongkol tertangkap terutama pada setengah bagian utara perairan, meliputi perairan sebelah timur wilayah Sumatera Utara dan Aceh Timur, serta perairan Aceh Utara sampai dengan
Banda Aceh. Demikian juga di Selat Malaka wilayah Malaysia, jenis ikan pelagis tersebut hanya tertangkap di perairan lepas Pantai Perlis, Kedah, Penang, Perak, dan Selangor' (Chee Phaik Ean, 2000). Ini disebabkan oleh kadar garam di perairan bagian utara Selat Malaka hampir selalu lebih tinggi dari 30 per mil sehingga sangat sesuai sebagai habitat jenis ikan pelagis yang hidup pada kadar

\footnotetext{
Peneliti pada Balai Riset Perikanan Laut, Muara Baru-Jakarta
} 
garam di atas 30 per mil antara lain ikan layang (Decapterus spp.) dan kembung (Rastrelliger spp.). Sedangkan di setengah perairan Selat Malaka bagian selatan seperti di daerah Riau, kadar garam hampir selalu kurang dari 30 per mil (Nurhayati, 2002), sehingga tidak sesuai sebagai tempat hidup ikan pelagis kecil terutama ikan layang.

Pukat cincin di perairan Selat Malaka ada 2 jenis menurut ikan target. Yang pertama adalah pukat cincin untuk menangkap ikan cakalang di perairan laut dalam yang terdapat di Banda Aceh (Bahar, 1984). Yang ke-2 untuk menangkap jenisjenis ikan pelagis kecil di perairan paparan seperti di perairan Aceh Timur juga di Banda Aceh dan timur Sumatera Utara. Sejak tahun 1970-an perikanan pukat cincin di perairan Selat Malaka berkembang pesat. Pada tahun 1975 jumlah kapal pukat cincin mencapai 114 unit, 7 unit antara lain berasal dari wilayah Nangro Aceh Darussalam dan 107 unit dari Sumatera Utara. Jumlah kapal pukat cincin terus meningkat sampai dengan tahun 1989 mencapai 1.068 unit atau 9 kali lebih besar dari jumlah pada tahun 1975 .

Dari tahun 1976 produksi ikan pelagis kecil terus meningkat sehingga pada tahun 1987 produksi ikan kembung (Rastrelliger spp.) dan ikan layang (Decapterus spp.) masing-masing mencapai 22.809 ton dan 16.163 ton, sehingga pada tahun tersebut nilai-nilai dugaan maximum sustainable yield ke-2 jenis ikan tersebut sudah terlewati (BOBP, 1987). Berkaitan dengan upaya penangkapan, tekanan penangkapan yang tertinggi berada di perairan pantai sedangkan di lepas pantai relatif ringan (Sivasubrahmaniam, 1985).

Menurut Sudjastani (1976), armada pukat cincin Selat Malaka diawali dengan pengadaan kapal kayu dengan bobot kurang dari 10 GT dan mesin 12 sampai dengan $17 \mathrm{HP}$ yang dipasang di luar (out board). Dimensi jaring yang digunakan setara dengan pukat cincin mini di utara Jawa (Potier \& Sadhotomo, 1995). Lama di laut dalam tiap trip hanya 1 hari.

Dari penelitian oleh Balai Penelitian Perikanan Laut pada tahun 1995 sampai dengan 1997 diperoleh informasi tentang perkembangan dimensi kapal, jaring, dan mesin penggerak sehingga terdapat 3 jenis armada yaitu armada pukat cincin mini, pukat cincin medium, dan pukat cincin besar. Di Belawan dan Tanjung Balai (Sumatera Utara), masing-masing 88 dan $69 \%$ terdiri atas kapal pukat cincin medium. Pukat cincin besar masing-masing 10 dan $20 \%$ sedangkan pukat cincin mini hanya 2 dan $12 \%$. Di Aceh Timur jumlah pukat cincin mini dan pukat cincin medium cukup berimbang, tetapi di Banda Aceh dan Aceh Utara didominasi kapal pukat cincin mini (Hariati et al., 2000).

Daerah penangkapan pukat cincin di Banda Aceh dan Aceh Utara adalah di perairan dekat masing-masing lokasi. Di Idi Rayeuk (Aceh Timur) daerah penangkapan pukat cincin medium adalah di perairan lepas pantai Aceh Timur, mulai dari Ujung Jambo Aye di sebelah utara sampai dengan Ujung Temiang yang berbatasan dengan wilayah Sumatera Utara. Daerah penangkapan pukat cincin mini dari Idi Rayeuk bahkan menempuh daerah penangkapan yang lebih jauh sampai dengan ke perairan ZEE di sebelah timur Laut Sabang. Armada pukat cincin (medium dan besar) Belawan juga beroperasi di perairan lepas pantai Aceh Timur dan di perairan Gosong Berhala (di lepas Pantai Belawan). Armada pukat cincin asal Tanjung Balai menangkap di lepas Pantai Sumatera Utara mulai dari Pulau Jemur di dekat perbatasan dengan wilayah Riau sampai dengan ke perairan Gosong Berhala (Hariati et al., 2000).

Laju tangkap ikan pelagis kecil yang tertinggi pada periode tahun 1995 sampai dengan 1997 di perairan Banda Aceh, perairan Aceh Timur dan perairan Sumatera Utara berlangsung masingmasing pada musim peralihan 1 (bulan Maret sampai dengan Mei), musim barat (bulan Desember sampai dengan Pebruari) dan pada musim timur (bulan Juni sampai dengan Agustus) (Hariati et al., 2001a).

Hasil analisis terhadap frekuensi panjang ikan banyar (Rastrelliger kanagurta) pada periode tahun 1995 sampai dengan 1997 dengan paket program FISAT diperoleh nilai-nilai dugaan parameter pertumbuhan $\mathrm{L}_{\circ 0}=32,7 \mathrm{~cm} F \mathrm{~L}$, dan $\mathrm{K}=0,75$; dan parameter mortalitas masing-masing $Z=3,07$, $M=1,12$ dan $F=1,95$. Dari nilai-nilai $F$ dan $Z$ diperoleh dugaan tingkat pengusahaan (E) 0,64 . Nilai $E$ tersebut tinggi, sehingga disarankan agar jumlah kapal pukat cincin di Selat Malaka tidak ditambah lagi (Hariati et al., 2001b).

Dari penelitian biologi reproduksi pada periode bulan Mei 2003 sampai dengan Desember 2004 antara lain diperoleh nilai-nilai dugaan panjang pertama kali matang gonad $\left(\mathrm{L}_{\mathrm{m}}\right)$ ikan layang dan banyar di Selat Malaka masing-masing $16 \mathrm{~cm} \mathrm{FL}$ dan $17 \mathrm{~cm}$ FL. Ke-2 nilai tersebut sama dengan yang diperoleh pada periode tahun 1995 sampai dengan 1997 (Hariati et al., 2005).

Dari statistik perikanan di wilayah pantai timur Sumatera Utara tahun 1975 sampai dengan 2003 
mengenai jumlah kapal pukat cincin dan produksi jenis-jenis ikan pelagis kecil (layang, kembung, selar, temban, dan japuh-Gambar 1b) diperoleh indikasi, bahwa pada tahun 1976 sampai dengan tahun 1982 terjadi peningkatan jumlah kapal yang beroperasi di perairan Selat Malaka (Gambar 1a). Peningkatan dari tahun 1978 sampai dengan tahun 1982 tidak diimbangi dengan peningkatan produksi ikan pelagis kecil melainkan terjadi penurunan produksi (Gambar 1b). Diduga pada periode tersebut penangkapan baru berlangsung di perairan pantai, yang kemudian mengalami kejenuhan.

Peningkatan jumlah kapal yang lambat dari tahun 1983 sampai dengan 1986 (Gambar 1a) bahkan menyebabkan kenaikan produksi ikan pelagis kecil yang nyata (Gambar 1b) Kemungkinan pada periode tersebut daerah penangkapan ikan pelagis kecil mulai berkembang ke arah lepas pantai, dengan eksploitasi sumber daya ikan pelagis yang jarang. Daerah penangkapan di lepas pantai yang berkembang terutama di perairan lepas Pantai Aceh Timur, Gosong Berhala serta di perairan Pulau Jemur.

Dari tahun 1987 terjadi peningkatan jumlah kapal yang pesat sampai dengan pada tahun 1990 mencapai puncak (Gambar 1a), banyak pengusaha yang tertarik menanamkan modal pada perikanan pukat cincin karena hasil tangkapan per kapal yang kembali meningkat. Antara tahun 1991 dan 1996

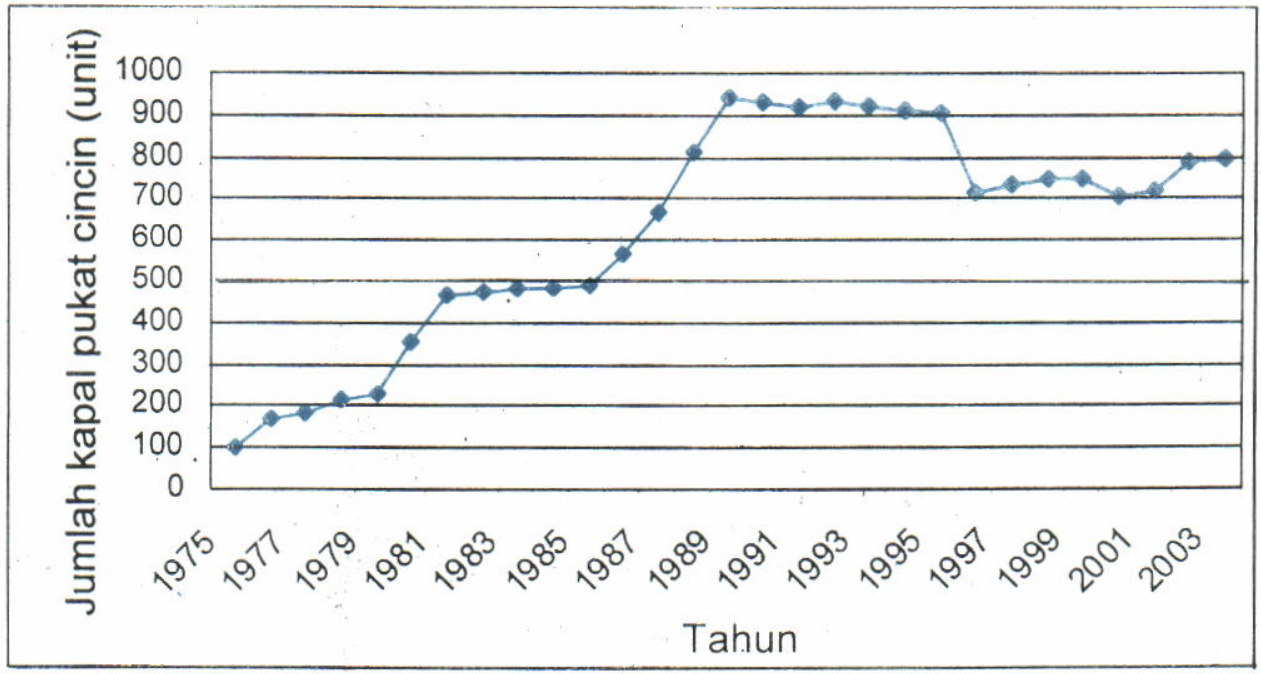

Gambar 1a. Jumlah kapal pukat cincin pantai timur Sumatera Utara tahun 1975 sampai dengan 2003. Figure 1a. Number of purse seiner in the east coast of North Sumatera region from 1975 to 2003.

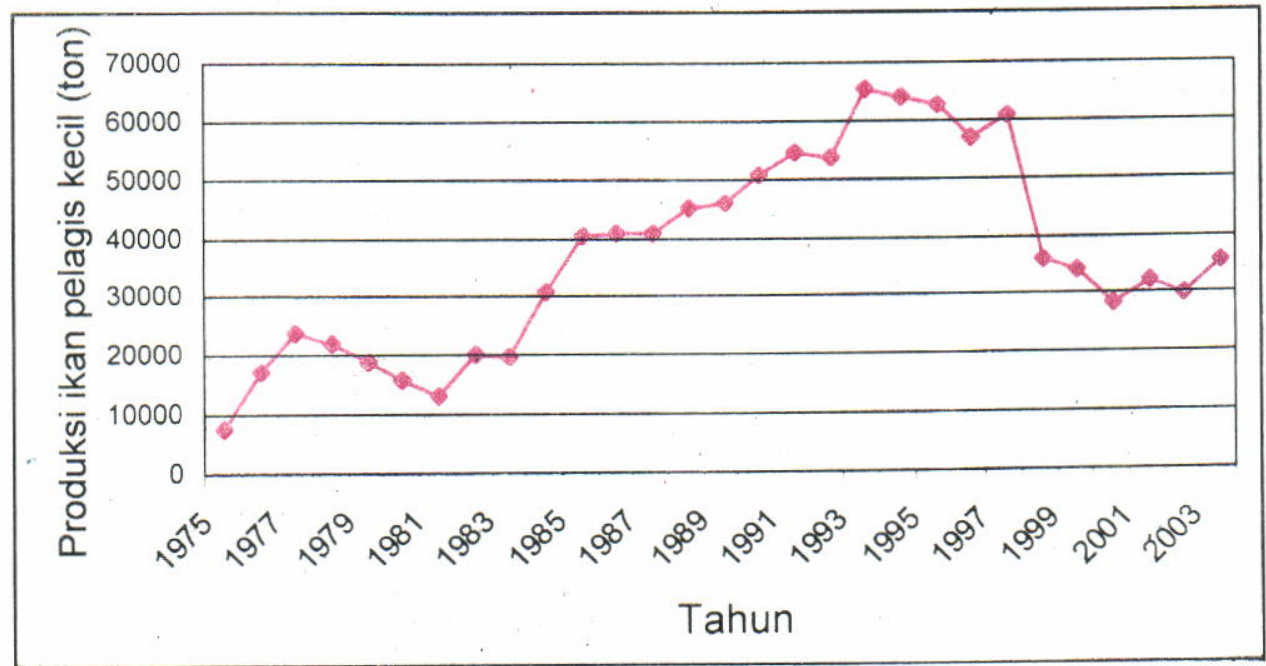

Gambar 1b. Total produksi jenis-jenis ikan pelagis kecil yang didaratkan di wilayah pantai timur Sumatera Utara tiap tahun dari tahun 1975 sampai dengan 2003.

Figure $1 \mathrm{~b}$. Yearly total production of the small pelagic fishes landed in the east coast of North Sumatera region from 1975 to 2003. 
pertambahan jumlah kapal tidak banyak, namun terjadi peningkatan dimensi kapal dan jaring dari armada pukat cincin Sumatera Utara, dari ukuran mini ke ukuran medium dan besar (Hariati et al., 2000), untuk memperlancar perjalanan dan pengoperasian jaring, juga meningkatkan hasil tangkapan.

Dari tahun 1996 sampai dengan 2000 terjadi penurunan jumlah kapal yang drastis, antara lain karena pada tahun 1996 dan 1997 terjadi cuaca yang buruk dengan asap tebal yang mengganggu jarak pandang dan pada tahun-tahun berikut faktor keamanan di daerah penangkapan yang tidak mendukung.

Sebagai hasil dari peningkatan jumlah dan dimensi armada pukat cincin, dari tahun 1987 produksi meningkat dan mencapai puncak pada tahun 1994. Seteiah itu, dari tahun 1995 sampai dengan 2001 cenderung turun karena jumlah kapal yang beroperasi juga turun. Mulai tahun 2001 sampai dengan 2003 ada indikasi terjadi peningkatan, baik jumlah kapal maupun produksi ikan pelagis kecil (Gambar 1b) diduga karena nelayan sudah mengetahui musim-musim ikan pelagis kecil di tiap daerah penangkapan. Dengan peningkatan dimensi kapal, dapat menempuh beberapa daerah penangkapan sesuai dengan musim, selain dapat menentukan jumlah hari per trip dan perbekalan.

Riset pemanfaatan sumber daya ikan pelagis kecil yang tertangkap dari Selat Malaka pada periode tahun 2003 sampai dengan 2004 yang dipusatkan di Kota Tanjung Balai, bertujuan untuk memperoleh data dan informasi tentang perkembangan upaya, antara lain aspek operasional kapal (jumlah trip dan jumlah hari di laut), daerah penangkapan, komposisi jenis hasil tangkapan, dan laju tangkap bulanan jenis jenis ikan pelagis kecil. Hasil penelitian diharapkan dapat digunakan sebagai masukan untuk kepentingan memvalidasi dan memperbaharui buku potensi perikanan tahun 2001 .

\section{BAHAN DAN METODE}

\section{Waktu dan Lokasi}

Riset sumber daya ikan pelagis kecil di Selat Malaka dilakukan dari bulan Mei 2003 sampai dengan April 2005 (2 tahun), terdiri atas 2 periode, periode pertama bulan Mei 2003 sampai dengan April 2004 dan periode ke-2 bulan Mei 2004 sampai dengan April 2005.
Riset dilakukan di salah satu lokasi kegiatan perikanan pukat cincin Selat Malaka yaitu Kota Tanjung Balai, Sumatera Utara yang merupakan salah satu pusat kegiatan pukat cincin di pantai timur wilayah Sumatera Utara.

\section{Pengumpulan Data dan Informasi}

\section{a. Hasil tangkapan dan jumlah hari di laut kapal contoh}

Pendaratan kapal pukat cincin di Tanjung Balai tidak terpusat di 1 tempat, melainkan tersebar di 25 tangkahan. Oleh tiap tangkahan, data produksi kapal tidak pernah dilaporkan ke Dinas Kelautan dan Perikanan Kota Tanjung. Tidak ada satupun data hasil tangkapan per kapal yang dapat dikutip dari Dinas Kelautan dan Perikanan, terutama sejak dihapus tempat pelelangan ikan di daerah ini sekitar tahun 1998. Data hasil tangkapan yang terinci menurut jenis ikan dalam tiap kapal contoh diperoleh dari para pengurus kapal pukat cincin yang sedang berbelanja perbekalan untuk trip kapal selanjutnya di salah satu toko (langganan), setelah menjual hasil tangkapan setiap trip. Pada tiap bulan dapat tercatat data hasil tangkapan dari 7 sampai dengan 11 kapal contoh. Informasi daerah penangkapan, lama di laut dan lama di perjalanan serta jumlah hari efektif (lama operasi) dalam tiap trip diperoleh juga dari nakhoda, anak buah kapal atau dari pengurus kapal.

\section{b. Jumlah trip tiap bulan}

Jumlah trip total seluruh kapal pukat cincin tiap bulan selama pengamatan dikutip dari data daftar harian nama-nama kapal perikanan yang mendarat, milik Kantor Administrasi Pelabuhan Tanjung Balai.

\section{c. Analisis}

Analisis data dilakukan untuk memperoleh dugaan hasil tangkapan total dan laju tangkap tiap bulan. Untuk menghitung hasil tangkapan total tiap bulan, hasil tangkapan per jenis ikan dari sejumlah trip kapal contoh pada tiap bulan dijumlah, Ialu dibagi dengan jumlah trip pada bulan yang sama, sehingga diperoleh nilai rata-rata hasil tangkapan per trip (A) pada tiap bulan. Hasil tangkapan total (B) tiap bulan diperoleh dengan cara mengalikan A dengan jumlah trip total kapal pukat cincin Tanjung Balai pada bulan yang sama.

Untuk menghitung laju tangkap tiap bulan (dalam kg per hari), terlebih dahulu dihitung jumlah hari efektif kapal pukat cincin tiap bulan (C). Laju 
tangkap tiap bulan diperoleh dari hasil tangkapan kapal contoh tiap bulan dibagi dengan nilai $\mathrm{C}$ pada bulan yang sama. Catch per unit of effort (laju tangkap tahunan, kg per hari) diperoleh dari total $B$ selama 1 tahun dibagi dengan total $C$ pada periode tahun yang sama.

Komposisi hasil tangkapan menurut jenis ikan selama periode bulan Mei 2003 sampai dengan April 2005 diperoleh dari persentase hasil tangkapan tiap jenis ikan.

\section{HASIL DAN PEMBAHASAN Upaya}

\section{a. Komposisi ukuran kapal pukat cincin Tanjung Balai}

Kapal pukat cincin Tanjung Balai yang beroperasi selama periode tahun 1995 sampai dengan 1997 berukuran 5 sampai dengan 88 GT (Tabel 1). Berdasarkan pada pengamatan bahwa ukuran pukat cincin mini pada umumnya di bawah $10 \mathrm{GT}$, pukat cincin medium antara 11 dan $50 \mathrm{GT}$, dan pukat cincin besar antara $51 \mathrm{GT}$ dan $>100 \mathrm{GT}$, pada tahun 1996 jumlah pukat cincin mini, medium dan besar, masing-masing 10, 140, dan 45 unit.

Pada tahun 2003 kisaran bobot kapal berkisar antara 5 dan $118 \mathrm{GT}$ dengan jumlah pukat cincin mini 5 unit, medium 106 unit, dan pukat cincin besar 124 unit. Dari Tabel 1 terlihat bahwa pada periode tahun 2003 terjadi penurunan jumlah pukat cincin mini (5 unit) dan medium (34 unit), serta penambahan jumlah pukat cincin besar (79 unit). Secara total, jumlah kapal pukat cincin di Tanjung Balai pada tahun 2003 bertambah 40 unit dari pada tahun 1996, atau dengan peningkatan sekitar 6 unit per tahun.
Dalam makalah ini, pukat cincin mini tidak akan dibahas karena jumlah semakin kecil dan daerah penangkapan terbatas di daerah pantai. Yang akan dibahas di sini adalah perkembangan upaya dan hasil tangkapan pukat cincin medium dan besar yang menggunakan alat bantu rumpon dan cahaya serta beroperasi di lepas pantai.

b. Jumlah trip, jumlah hari di laut, dan aktivitas penangkapan

Jumlah trip total kapal pukat cincin Tanjung Balai selama tahun 2003 dan 2004 turun daripada tahun 1996 dan 1997 (Tabel 2). Penurunan jumlah trip tersebut terutama akibat dari peningkatan jumlah hari di laut dalam tiap trip. Jumlah hari efektif tiap trip pada tahun 1996 dan 1997 masingmasing 2,5 hari dan 3,5 hari dengan lama di perjalanan 1 hari pulang pergi, sehingga jumlah hari di laut pada tiap trip masing-masing 3,5 hari dan 4,5 hari. Pada tahun 2003 dan 2004 jumlah hari efektif bertambah masing-masing menjadi 4,8 hari dan 4,7 hari per trip, ditambah dengan lama di perjalanan 2,0 hari, sehingga jumlah hari di laut tiap trip semakin lama sampai dengan 6,8 dan 6,7 hari.

Selama tahun 1996 dan 1997 aktivitas yang tinggi kapal pukat cincin Tanjung Balai terjadi pada musim Timur (bulan Juni sampai dengan Agustus) dan musim peralihan 2 (bulan September sampai dengan Nopember). Aktivitas pukat cincin yang rendah terjadi pada musim barat (bulan Desember sampai dengan Pebruari) dan musim peralihan 1 (Hariati et al., 2001a).

Jumlah hari efektif pukat cincin Tanjung Balai tiap bulan pada periode bulan Mei 2003 sampai dengan April 2004 dan periode bulan Mei 2004 sampai dengan April 2005 berfluktuasi (Gambar 2).

Tabel 1

Table 1.

Komposisi ukuran kapal pukat cincin di Tanjung Balai tahun 1996 dan 2003 Size composition of purse seiner in Tanjung Balai in 1996 and 2003

\begin{tabular}{cccc}
\hline $\begin{array}{c}\text { Kisaran ukuran kapal/ } \\
\text { Range of vessel size }\end{array}$ & \multicolumn{2}{c}{$\begin{array}{c}\text { Jumlah kapal (unit) pada tahun/ } \\
\text { Number of vessel (unit) in year: }\end{array}$} & $\begin{array}{c}\text { Kategori pukat cincin/ } \\
\text { Purse seine category }\end{array}$ \\
\cline { 2 - 4 } (GT) & 1996 & 2003 & Mini \\
$11-10$ & 10 & 5 & Medium \\
$11-20$ & 18 & 21 & \\
$21-30$ & 26 & 81 & Besar \\
$31-40$ & 93 & 2 & \\
$41-50$ & 3 & 5 & \\
$51-60$ & 8 & 23 & \\
$61-70$ & 14 & 49 & 14 \\
$71-80$ & 6 & 10 & 23 \\
$81-90$ & 17 & 235 \\
$91-100$ & 0 & & \\
$>100$ & 0 & 195 & 23 \\
\hline
\end{tabular}


Tabel 2. Jumlah trip kapal pukat cincin Tanjung Balai tiap bulan pada tahun 1996 dan 1997 serta tahun 2003 dan 2004

Table2. Monthly number of trip of Tanjung Balai's purse seieners of during 1996 and 1997; and 2003 and 2004

\begin{tabular}{lcccc}
\hline \multirow{2}{*}{$\begin{array}{c}\text { Bulan/ } \\
\text { Month }\end{array}$} & \multicolumn{5}{c}{ Jumlah trip pada tahun/Trip number in year. } \\
\cline { 2 - 5 } & $\mathbf{1 9 9 6}$ & $\mathbf{1 9 9 7}$ & $\mathbf{2 0 0 3}$ & $\mathbf{2 0 0 4}$ \\
\hline Januari & 555 & 453 & 381 & 358 \\
Pebruari & 500 & 543 & 326 & 381 \\
Maret & 539 & 607 & 386 & 413 \\
April & 644 & 597 & 420 & 386 \\
Mei & 647 & 662 & 543 & 394 \\
Juni & 726 & 717 & 459 & 408 \\
Juli & 729 & 762 & 489 & 429 \\
Agustus & 748 & 837 & 426 & 516 \\
September & 713 & 815 & 504 & 504 \\
Oktober & 776 & 789 & 485 & 324 \\
Nopember & 740 & 710 & 412 & 440 \\
Desember & 698 & 756 & 403 & $\mathbf{4 9 7 4}$ \\
\hline Total & $\mathbf{8 0 1 5}$ & $\mathbf{8 2 4 8}$ & $\mathbf{5 2 3 4}$ & \\
\hline
\end{tabular}

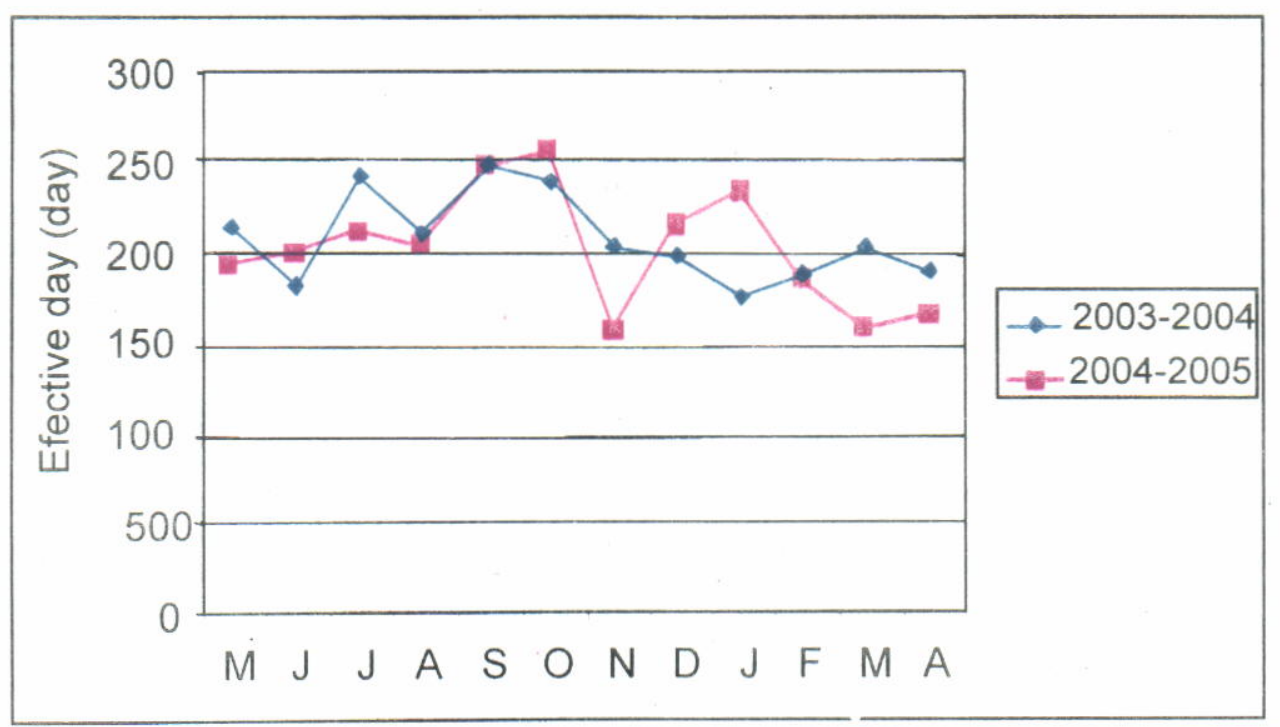

Gambar 2. Jumlah hari di laut efektif pukat cincin Tanjung Balai pada periode tahun 2003 sampai dengan 2004 dan tahun 2004 sampai dengan 2005.

Figure 2. Number of effective days of Tanjung Balai's purse seiners in the period of 2003 to 2004 and of 2004 to 2005 .

sampai dengan Oktober 2004 (musim peralihan 2) juga pada bulan Januari (barat). Sedangkan yang terendah terjadi lebih awal yaitu pada bulan Nopember 2004 (menjelang musim barat) dan pada bulan Maret sampai dengan April (peralihan 1). Puncak-puncak aktivitas kapal pukat cincin Pada periode yang pertama, jumlah hari efektif tertinggi terjadi pada bulan Juli (timur) dan bulan September sampai dengan Oktober 2003 (musim peralihan 2); terendah pada bulan Januari 2004 (barat). Pada periode ke-2, jumlah hari efektif tertinggi terjadi selain pada bulan September
Tanjung Balai selama periode riset ini berlangsung pada musim yang sama dengan pada periode tahun 1996 dan 1997. Total hari di laut efektif pada periode pertama dan ke-2 masing-masing 25.293 hari, dan 24.772 hari.

\section{Daerah Penangkapan}

Dalam periode tahun 2003 sampai dengan 2005, armada pukat cincin Tanjung Balai telah beroperasi sampai dengan ke perairan Aceh Timur, yang juga merupakan daerah penangkapan bagi 
armada-armada pukat cincin asal Belawan dan Aceh Timur (Langsa dan Idi). Perairan Gosong Berhala (di lepas Pantai Belawan) juga merupakan daerah penangkapan utama bagi armada pukat cincin yang beroperasi di Selat Malaka khusus yang berasal dari Tanjung Balai. Ke-2 daerah penangkapan tersebut terletak di sebelah utara Tanjung Balai.

Namun, dalam periode tersebut perairan dari Batu Putih (di lepas Pantai Tanjung Balai) sampai dengan ke Pulau Jemur (perbatasan dengan wilayah Riau) tidak lagi ditempuh armada Tanjung Balai, menurut beberapa orang nelayan, hasil tangkapan yang diperoleh dari daerah-daerah penangkapan tersebut sangat kurang dibandingkan dengan hasil tangkapan dari perairan Aceh Timur dan Gosong Berhala.

Berdasarkan pada pengamatan tim survei laut Balai Penelitian Perikanan Laut dengan menggunakan Kapal Riset Bawal Putih I pada tahun 1995 dan 1996 di perairan Aceh Timur dan Gosong Berhala (dalam Hariati \& Sriyati, 2000) kedalaman rata-rata di dekat pantai berkisar antara 24 dan $50 \mathrm{~m}$, sedangkan di lepas pantai antara 40 dan $100 \mathrm{~m}$. Semakin ke arah Aceh Timur-utara Aceh, kedalaman perairan makin meningkat, seperti telah dinyatakan belum dalam Martosubroto \& Naamin (1985).

Menurut Nugroho (1985) pada bulan Nopember 1984 (akhir musim peralihan 2), kepadatan stok ikan pelagis kecil di perairan timur Sumatera (bagian utara Selat Malaka, paparan benua) antara
67.000 dan 69.000 ton, sedangkan di sebelah utara Aceh (laut dalam) hanya berkisar antara 16.000 dan 17.300 ton. Selain itu, kelompok ikan pelagis cenderung berada di perairan sebelah timur Sumatera. Mengingat kepadatan sumber daya ikan pelagis kecil di bagian timur Sumatera tersebut yang relatif tinggi, maka perairan Aceh Timur dan Gosong Berhala merupakan daerah penangkapan ikan pelagis yang utama bagi armada pukat cincin Selat Malaka.

\section{Hasil Tangkapan}

\section{a. Komposisi hasil tangkapan}

Hasil tangkapan total pukat cincin Tanjung Balai pada periode bulan Mei 2003 sampai dengan April 2005 diduga 39.405 ton, sedangkan dugaan hasil tangkapan pada tahun 1996 dan 1997 masingmasing $20.216,7$ dan 50.930 ton.

Ikan pelagis kecil merupakan bagian terbesar (78\%) dari hasil tangkapan yang terdiri atas 5 kategori jenis. Dari Gambar 3, jenis yang paling dominan antara lain adalah ikan layang, yang terdiri atas 2 spesies yaitu ikan layang pipih (Decapterus russelli) dan ikan layang bulat (D. macrosoma). Menyusul ikan banyar (Rastrelliger kanagurta), selar kuning (Selaroides leptolepis), bentong (Selar crumenophthalmus), dan tembang (Sardinella gibbosa). Jenis ikan tongkol (Auxis thazard-pelagis besar) $14 \%$; dan jenis-jenis ikan lain antara lain tetengkek, layur, alu-alu, dan anak ikan bronang $8 \%$.

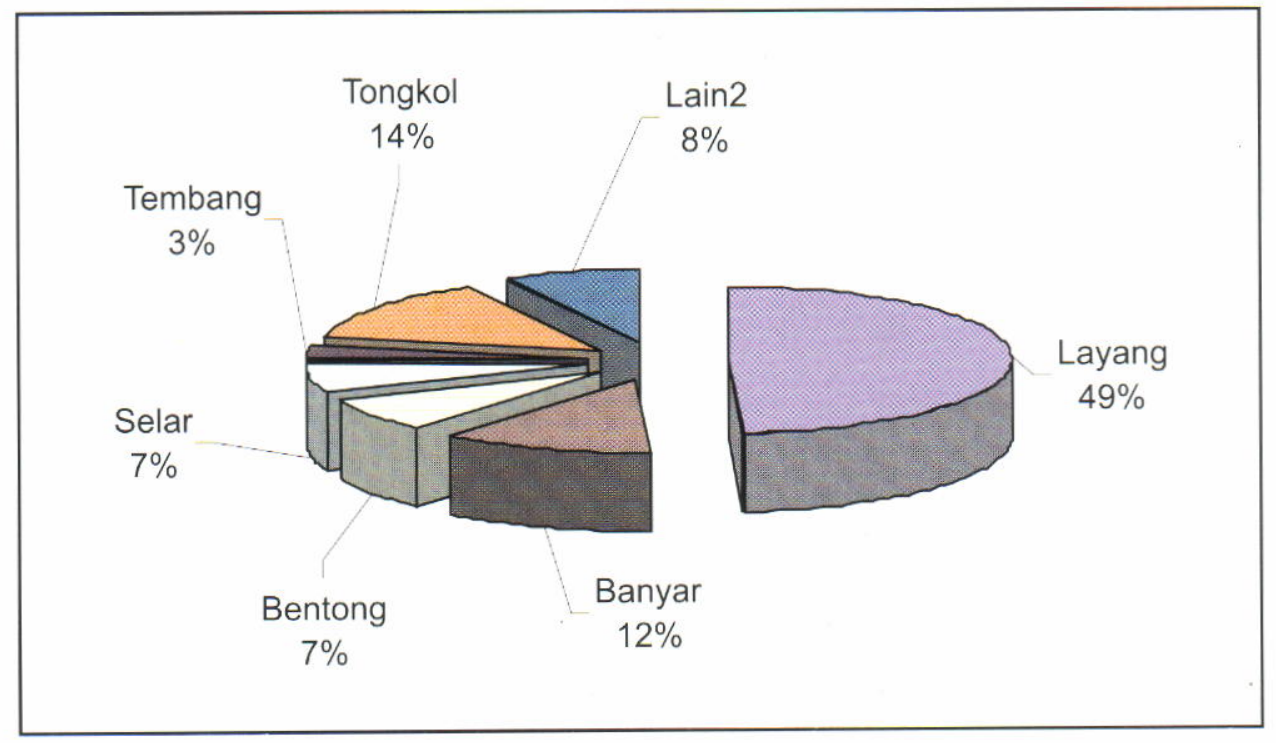

Gambar 3. Komposisi hasil tangkapan pukat cincin Tanjung Balai dari bulan Mei 2003 sampai dengan April 2005.

Figure 3. Catch composition of Tanjung Balai's purse seiner from May 2003 to April 2005. 
Pada periode tahun 1995 sampai dengan 1997 hasil tangkapan pukat cincin Tanjung Balai didominasi oleh ikan banyar (38\%), menyusul ikan kembung $(18 \%)$, ikan bentong $(14 \%)$, dan ikan layang $(15 \%)$ yang terdiri atas layang pipih (12\%) dan layang bulat $(3 \%)$. Jenis ikan lain yang terdapat dalam hasil tangkapan terdiri atas ikan tembang, selar, dan tetengkek (Hariati et al., 2001a). Pada periode tahun 2003 sampai dengan 2004 telah terjadi perubahan komposisi hasil tangkapan pukat cincin Tanjung Balai. Perubahan tersebut disebabkan oleh perkembangan daerah penangkapan pukat cincin, dari perairan pantai (costal neritik) yang berkadar garam relatif rendah ke perairan lepas pantai (neritik dan neritik oseanik) yang berkadar garam lebih tinggi, sehingga pada periode tahun 2003 sampai dengan 2004 ikan kembung ( $R$. brachyosoma) tidak lagi ditemukan dalam hasil tangkapan pukat cincin medium dan besar. Spesies tersebut tertangkap di wilayah perairan pantai timur Sumatera Utara dengan alat tangkap pukat cincin mini dan jaring insang hanyut.

Dalam periode tahun 2003 sampai dengan 2004 dan tahun 2004 sampai dengan 2005 (Gambar 3), persentase ikan banyar dan bentong berkurang dibandingkan dengan persentase pada tahun 1996 dan 1997. Di lain pihak, persentase total ke-2 jenis ikan layang (Decapterus russelli dan $D$. macrosoma) bertambah dari hanya $15 \%$ pada tahun 1996 sampai dengan 1997 menjadi 49\%. Pada beberapa kali pengambilan contoh, proporsi ke-2 jenis ikan layang tersebut hampir seimbang.

Dari tahun 1969 sampai dengan 1997 di perairan Selat Malaka wilayah Malaysia, ikan pelagis tertangkap oleh trawl, jaring insang hanyut, dan pukat cincin. Hasil tangkapan tiap tahun yang terutama (20 sampai dengan $80 \%$ ) dari perairan ini adalah kategori jenis ikan kembung yang terdiri atas Rastrelliger kanagurta, R. Brachyosoma, dan R.faughni. Hasil tangkapan lain terdiri atas ikan selar, layang, sarden, dan lain-lain (Chee Phaik Ean, 2000). Spesies ikan kembung yang paling dominan belum diketahui. Beberapa hasil pengamatan ada yang menyebut $R$. kanagurta (ikan banyar), dan ada yang menyebut $R$. brachyosoma. Di perairan ini $R$. brachyosoma merupakan hasil sampingan yang dominan dari alat tangkap trawl dan juga hasil tangkapan utama dari jaring insang hanyut. Sementara itu, $R$. kanagurta lebih dominan di dalam hasil tangkapan pukat cincin yang dioperasikan dengan bantuan rumpon dan cahaya. Namun, diyakini bahwa $R$. faughni tertangkap dengan volume yang tidak signifikan. Selanjutnya, Chee Phaik Ean (2000) menyarankan, agar dalam statistik perikanan dicantumkan produksi ikan menurut jenis alat tangkap, agar produksi tiap spesies dapat diestimasi dengan lebih mudah.

\section{c. Laju tangkap tahunan (Catch per unit of effort)}

Dalam periode tahun 2003 sampai dengan 2004 dan tahun 2004 sampai dengan 2005, laju tangkap jenis-jenis ikan pelagis kecil (layang, banyar, selar, dan tembang), juga laju tangkap total dan laju tangkap ikan lain-lain turun, kecuali laju tangkap ikan bentong dan tongkol naik (Tabel 3). Jumlah gabungan laju tangkap ke-5 jenis ikan pelagis kecil tersebut pada periode tahun 2003 sampai dengan 2004 dan tahun 2004 sampai dengan 2005 masingmasing $710,9 \mathrm{~kg}$ per hari dan $521,0 \mathrm{~kg}$ per hari. Pada tahun 1996 dan 1997, catch per unit of effort ikan pelagis kecil masing-masing $935,9 \mathrm{~kg}$ per hari dan $1.831,7 \mathrm{~kg}$ per hari (Hariati et al., 2000). Laju tangkap kelompok ikan pelagis kecil pada ke-2 periode pengamatan ini mengalami penurunan dari periode tahun 1996 dan 1997. Diduga karena eksploitasi sumber daya ikan pelagis kecil di Selat Malaka pada periode pengamatan ini sudah semakin tinggi.

\section{c. Laju tangkap bulanan ikan layang (Decapterus russelli) dan ikan banyar (Rastrelliger kanagurta)}

Fluktuasi laju tangkap total pukat cincin Tanjung Balai bulanan mengikuti pola fluktuasi laju tangkap ikan layang dan puncak puncak laju tangkap total terjadi pada bulan bulan yang sama dengan

Tabel 3. Laju tangkap jenis-jenis ikan pelagis kecil, tongkol, ikan lain-lain dan laju tangkap total perikanan pukat cincin Tanjung Balai di Selat Malaka pada periode tahun 2003 sampai dengan 2004 dan tahun 2004 sampai dengan 2005

Table 3. Catch per unit of effort of small pelagics, litlle tuna, others and the total catch per unit of effort of purse seine fishery of Tanjung Balai in the Straits of Malacca, periods of 2003 to2004 and of 2004 to 2005

Laju tangkap tahunan (kg per hari)/Catch per unit of effort ( $\mathrm{kg}$ per day)

\begin{tabular}{ccccccccc}
\hline & Layang & Banyar & Bentong & Selar & Tembang & Tongkol & Lain-lain & Total \\
\hline $2003-2004$ & 444,2 & 102,3 & 55,1 & 71,4 & 37,8 & 94,8 & 121,1 & 926,7 \\
$2004-2005$ & 326,7 & 90,3 & 62,5 & 31,4 & 10,0 & 122,1 & 1,3 & 644,4 \\
\hline
\end{tabular}




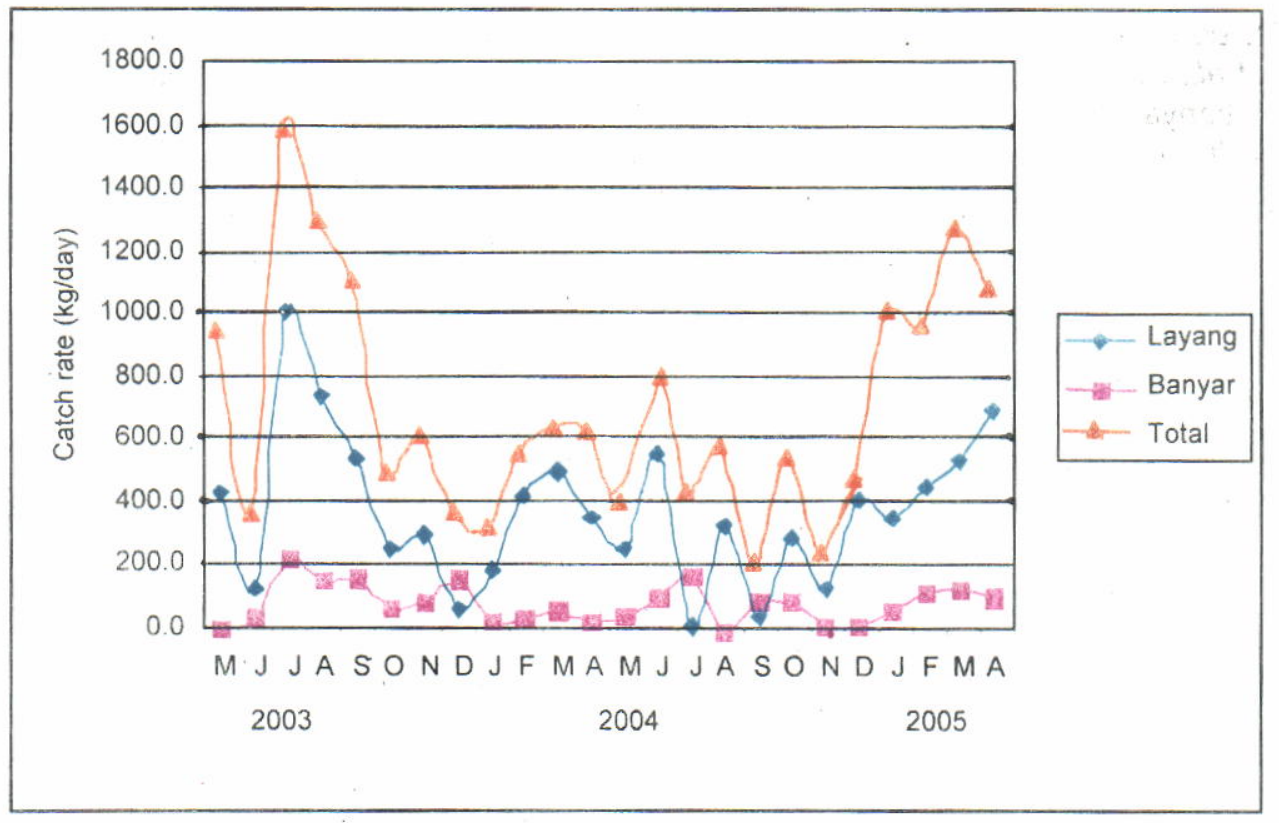

Gambar 4. Laju tangkap total dan laju tangkap 2 jenis ikan pelagis kecil dominan dari hasil tangkapan pukat cincin Tanjung Balai dari bulan Mei 2003 sampai dengan April 2005.

Figure 4. Total catch per unit of effort and catch per unit of effort of 2 dominant small pelagic fishes from the catch of Tanjung Balai's purse seiner from May 2003 to April 2005.

puncak-puncak laju tangkap ikan laying (Gambar 4).

Dalam Gambar 4 juga terlihat, puncak-puncak laju tangkap ikan layang terjadi pada bulan Juli dan Agustus 2003 (musim timur), bulan Maret (peralihan 1), bulan Juni dan Agustus 2004 (timur), serta bulan April 2005 (peralihan 1). Hal tersebut sesuai dengan hasil penelitian Hariati et al. (2001a), bahwa musim ikan layang di Selat Malaka yaitu di perairan timur Sumatera berlangsung pada musim timur dan musim peralihan 2, serta di perairan Aceh Timur terjadi pada musim barat dan musim peralihan 1 .

Jika musim pemijahan ikan layang (D. russelli) di perairan Selat Malaka berlangsung antara bulan April dan Oktober, dengan puncak pemijahan terjadi pada bulan Oktober (Hariati et al. 2005). Tampak musim pemijahan ikan layang di Selat Malaka terjadi pada saat laju tangkap sedang menurun. Seperti terlihat dalam Gambar 4., antara bulan Agustus sampai dengan Oktober 2003 dan bulan April sampai dengan Oktober 2004 laju tangkap ikan layang cenderung turun. Diduga ada hubungan dengan perilaku ruaya ikan dewasa yang matang gonad ke daerah pemijahan, sehingga ikan yang tertangkap hanya ikan muda. Sebaliknya, di luar musim pemijahan yaitu antara bulan Januari sampai dengan Maret 2004 dan Desember 2004 sampai dengan April 2005, laju tangkap ikan layang cenderung naik.
Dari Gambar 4 juga terlihat, bahwa puncakpuncak laju tangkap ikan banyar terjadi pada bulan-bulan Juli (musim timur) dan bulan Desember 2003 (musim barat); bulan Juli 2004 (musim timur), bulan September sampai dengan Oktober 2004 (musim peralihan 2), dan bulan Maret 2005 (musim peralihan 1). Menurut Hariati et al. (2001a), musim laju tangkap ikan banyar di perairan timur Sumatera Utara terjadi pada musim barat, timur, dan peralihan 2, sedangkan di perairan Aceh Timur pada musim barat, peralihan 1, dan timur. Dari puncak-puncak laju tangkap yang diperoleh pada setiap musim dari ke-2 jenis ikan target (layang dan banyar) pada periode penelitian ini ada indikasi para nelayan pukat cincin Tanjung Balai telah dapat memilih daerah penangkapan yang harus ditempuh untuk memperoleh hasil tangkapan yang optimal.

Musim pemijahan ikan banyar di Selat Malaka terjadi terutama antara bulan Mei dan Oktober serta antara bulan Desember sampai dengan Pebruari, dengan puncak-puncak pada bulan Juli dan Oktober (Hariati et al., 2005). Namun untuk $R$. kanagurta, puncak-puncak laju tangkap ikan banyar tersebut banyak terjadi pada puncak serta pada periode musim pemijahan, seperti pada bulan Juli tahun 2003 dan Juli 2004, bulan Oktober 2004, serta Desember 2003. Pada bulan Juli 2004 diperoleh contoh ikan banyar betina yang (hampir) selesai memijah (almost spent, tingkat kematangan gonad 5) dalam persentase jumlah spesimen yang 
tinggi (84\%), berukuran 19 sampai dengan $23 \mathrm{~cm}$ FL (Hariati et al., 2005). Pada bulan Juli 2004, laju tangkap ikan banyar tinggi, karena ikan besar yang baru kembali dari daerah pemijahan ikut tertangkap.

\section{KESIMPULAN DAN SARAN}

Kesimpulan yang dapat ditarik dari riset ini adalah:

1. Dari tahun 1996 sampai dengan tahun 2003 jumlah kapal pukat cincin di Tanjung Balai meningkat sekitar 6 unit per tahun.

2. Daerah penangkapan pukat cincin Tanjung Balai selama pengamatan, selain di seputar perairan Gosong Berhala (lepas Pantai Belawan) juga telah berkembang ke arah utara (sebelah utara perairan Aceh Timur), sedangkan perairan-perairan Batu Putih (lepas Pantai Tanjung Balai) dan Pulau Jemur (dekat perbatasan dengan wilayah Riau sudah ditinggalkan.

3. Meskipun jumlah trip kapal pukat cincin Tanjung Balai selama tahun 2003 (5.234 trip) dan tahun 2004 (4.974 trip) turun dibandingkan dari tahun 1996 (8.015 trip) dan tahun 1997 (8.634 trip), jumlah hari di laut (lama di perjalanan ditambah jumlah hari efektif) dalam tiap trip pada tahun 2003 (6,8 hari), dan tahun 2004 (6,7 hari) bertambah, karena daerah penangkapan yang semakin jauh dan jumlah hari efektif yang bertambah.

4. Puncak-puncak aktivitas (jumlah trip) kapal pukat cincin Tanjung Balai selama tahun 2003 sampai dengan 2004 seperti pada periode tahun 1996 sampai dengan 1997, terjadi pada musim timur dan musim peralihan II.

5. $86 \%$ dari hasil tangkapan pukat cincin Tanjung Balai terdiri atas jenis-jenis ikan pelagis kecil yang didominasi oleh jenis ikan layang (Decapterus spp., 49\%). Sedang pada periode tahun 1996 sampai dengan 1997 jenis ikan pelagis kecil yang dominan adalah ikan banyar dan kembung (Rastrelliger spp.) sekitar 56\%.

6. Laju tangkap jenis-jenis ikan pelagis kecil pada periode tahun 2003 sampai dengan 2004 dan periode tahun 2004 sampai dengan 2005 masing-masing $710,9 \mathrm{~kg}$ per hari dan $521,0 \mathrm{~kg}$ per hari, turun dari laju tangkap ikan pelagis kecil pada periode tahun 1996 sampai dengan 1997 masing-masing $935,9 \mathrm{~kg}$ per hari dan $1.831,7 \mathrm{~kg}$ per hari.
7. Puncak-puncak laju tangkap ikan layang terjadi pada bulan Juli dan Agustus 2003 (musim timur), bulan Maret (peralihan 1), bulan Juni dan Agustus 2004 (timur), serta bulan April 2005 (peralihan 1).

8. Puncak-puncak laju tangkap ikan banyar terjadi pada bulan Juli (musim timur) dan Desember 2003 (musim barat); bulan Juli 2004 (musim timur), bulan September sampai dengan Oktober 2004 (musim peralihan 2), dan bulan Maret 2005 (musim peralihan 1).

Sebagai saran, untuk kelestarian sumber daya ikan pelagis kecil, jumlah kapal pukat cincin Tanjung Balai yang diberi izin beroperasi di perairan Selat Malaka wilayah Indonesia saat ini tidak ditambah lagi. Mengingat dengan penambahan 40 unit kapal pukat cincin di Tanjung Balai dari tahun 1997 telah menyebabkan penurunan laju tangkap.

\section{DAFTAR PUSTAKA}

Bahar, S. 1984. Studi teknologi pukat cincin cakalang di perairan Daerah Istimewa Aceh. Jurnal Penelitian Perikanan Laut. No.85. Hal. 9-18.

BOBP. 1987. Investigation on mackereles and scads resources of Malacca Strait. Marine Resources Management in the Bay of Bengal, Colombo. BOBP/REP/39. 149 pp.

Chee Phaik Ean, 2000. The status of the Rastrelliger (kembung) fishery on the west coast of Peninsula Malaysia. Fish Code Management Supplement To Report of a Workshop on the Fishery and Management of Short Mackerel (Rastrelliger spp.) on the West Coast of Peninsula Malaysia. FAO of the UN. Roma. p 1-20.

Hariati, T., M. Taufik, \& A. Zamroni. 2005. Beberapa aspek reproduksi ikan layang (Decapterus russelli) dan ikan banyar (Rastrelliger kanagurta) di perairan Selat Malaka Indonesia. Jurnal Penelitian Perikanan Indonesia Edisi Sumber Daya dan Penangkapan. Vol.II. No.2. Hal. 47-56.

Hariati, T. \& E. Sriyati. 2000. Keragaman jenis ikan pelagis kecil yang tertangkap pukat cincin di Selat Malaka. Prosiding Seminar Nasional Keanekaragaman Hayati Ikan. 6 Juni 2000. Institut Pertanian Bogor-Lembaga IImu Pengetahuan Indonesia. 205-210. 
Hariati, T. D. Nugroho, \& E. S. Girsang. 2000. Perkembangan pukat cincin di Selat Malaka. Jurnal Penelitian Perikanan Indonesia. Vol.6. No.2. Hal. 43-51.

Hariati, T., E. Sriyati, \& S. Mardliyah. 2001a. Perubahan musiman komposisi hasil tangkapan dan kelimpahan ikan pelagis kecil di perairan Selat Malaka. Jurnal Penelitian Perikanan Indonesia. Vol.7 No.1. Hal. 53-61.

Hariati, T, G. S. Mertha, \& Sujianto. 2001b. Tingkat pengusahaan sumber daya ikan banyar (Ratrelliger kanagurta) di perairan Selat Malaka. Jurnal Penelitian Perikanan Indonesia. Vol.7 No.4. Hal. 31-37.

Martosubroto, P. \& Naamin, N. 1985. Fisheries of the Malacca Straites with special refrences to the environmentes. Presented to The Symposium on Environmental Research and Coastal Zone Management Problem in the Strait of Malacca, in Medan. RIMF : 16 p

Nugroho, D. 1985. Potensi sumber daya perikanan pelagis kecil di perairan sebelah utara dan timur Sumatera. Jurnal Penelitian Perikanan Laut. No.33. Hal. 11-20.

Nurhayati. 2002. Karakteristik hidrografi dan arus di perairan Selat Malaka, di perairan selat Indonesia: Oseanografi, Biologi, dan Lingkungan. Pusat Penelitian Oseanografi. Lembaga IImu Pengetahuan Indonesia. Jakarta. hal 1-8.

Potier, M. \& B. Sadhotomo. 1995. Seiners fisheries in Indonesia. M. potier \& S. Nurhakim (eds). Biology. Dynamic, Exploitation of the small pelagic Fisheries in the Java Strait. AARDOSTORM. p. 195-214.

Sivasubrahmaniam, K. 1995. Marine Fishery Resources of the Bay of Bengal. BOBPNNP/36. FAO-UNDP. 66 p.

Sudjastani, T. 1976. Pelagic fisheries of Indonesia in the Malacca Strait. Report of the Workshop on the Fishery Resources of the Malaca Strait. Part I: 29 March to 2 April 1976. Jakarta Work Plan Implementation (General) SCS/GEEN/76/2. SCSFDCP. Manila. p 48-60. 
